\title{
New fossil remains from the Pliocene Koetoi Formation of northern Japan provide insights into growth rates and the vertebral evolution of porpoises
}

Mizuki Murakami, Chieko Shimada, Yoshinori Hikida, and Hiromichi Hirano

Acta Palaeontologica Polonica 60 (1), 2015: 97-111 doi: http://dx.doi.org/10.4202/app.2012.0127

Extant porpoises (Phocoenidae) are odontocetes characterized by their small size, short and wide rostrum, late (or absent) completion of epiphyseal ankylosis in the vertebral column (= physical maturity), and short life cycles, all of which are thought to have resulted from progenetic evolution. We describe a small fossil phocoenid from the lower Pliocene Koetoi Formation of Hokkaido (northern Japan), preserving a small, narrow rostrum, as well as anteroposteriorly elongate thoracic and lumbar vertebral centra with completely fused epiphyses. Physical maturity in this specimen occurred significantly earlier than in extant phocoenids, as shown by dental data indicating that the specimen died at only four years of age. The difference between the present material and extant porpoises may be attributable to different growth rates during ontogeny. The long centra and caudally inclined neural spines of the specimen from Hokkaido are primitive characters among phocoenids. By contrast, the great height of its neural spines is highly derived, even among extant species, and suggestive of a fast swimmer. In terms of its vertebral morphology, the new specimen falls within a morphological continuum defined by the archaic Numataphocoena yamashitai and the highly derived vertebral morphology of Phocoenoides dalli. Phocoenid vertebral evolution has been complex and frequently convergent, as opposed to stepwise and unidirectional. The different vertebral morphologies of the new specimen and the contemporaneous extinct taxa Numataphocoena and Piscolithax longirostris indicate that they were adapted to different environments.

Key words: Mammalia, Phocoenidae, age estimation, growth rate, vertebral evolution, Pliocene, Japan.

Mizuki Murakami [mizuki-m@aoni.waseda.jp], Department of Earth Sciences, Faculty of Education and Integrated Arts and Sciences, Waseda University, Nishiwaseda 1-6-1, Shinjuku, Tokyo 169-8050, Japan; Chieko Shimada [c-shimada@aist.go.jp ], Mineral Industry Museum, Akita University, 28-2 Tegata-Osawa, Akita 010-8502, Japan; Geological Survey of Japan, National Institute of Advanced Industrial Science and Technology, 1-1-1 Higashi, Tsukuba 305-8567, Japan; Yoshinori Hikida [nmhikida@coral.ocn.ne.jp], Nakagawa Museum of Natural History, 28-9, Yasukawa, 
Nakagawa-cho, Hokkaido 098-2626, Japan; Hiromichi Hirano, Department of Earth Sciences, Faculty of Education and Integrated Arts and Sciences, Waseda University, Nishiwaseda 1-6-1, Shinjuku, Tokyo 169-8050, Japan (passed away on 5 May 2014).

This is an open-access article distributed under the terms of the Creative Commons Attribution License (for details please see creativecommons.org), which permits unrestricted use, distribution, and reproduction in any medium, provided the original author and source are credited.

FoF Full text $(657.9 \mathrm{kB})$ ।

Fof Supplementary file $(230.7 \mathrm{kB})$ 